\title{
Journal of Scheduling (2016)
}

\author{
Edmund Burke ${ }^{1}$. Michael Pinedo ${ }^{1}$
}

Published online: 10 February 2016

(C) Springer Science+Business Media New York 2016

Welcome to Volume 19 of the Journal of Scheduling. It is hard to believe that all those years have passed since we were preparing a submission to launch a brand new journal. At the time, we believed that we had seen a gap in the landscape for a journal on all aspects of scheduling research, which cuts across disciplines and which cuts across theory and practice. The intervening years have demonstrated that there had indeed been such a gap. Over the years, the journal has become a significant forum for internationally leading research, and it has contributed towards enabling a multidisciplinary perspective on major research advances in the field. We continue to support special issues of the journal on specific areas of scheduling research or which are focussed on specific conferences. Moreover, we continue to encourage review and survey papers from across the field.

According to eigenfactor.org, using its Article Influence score, the journal is ranked 21st out of 69 journals in the Operations Research and Management Science category. Our ranking in the SCImago Journal and Country Rank is 20th out of 117 outlets in the category entitled, Management Science and Operations Research, placing us comfortably in the top quartile. Our current Thompson Reuters impact factor is 1.028 , which is a slightly down from last year. It places us in 44th position (from 81 journals) in the Operations Research and Management Science category. However, our 5-Year Impact Factor is 1.789 , and our position improves to 27 th on this measure. Moreover, it moves to 21 st if article influence is employed. The journal continues its trend in recent years of good performance with respect to article influence measures. Between January and October 2015, the number of article downloads was 31,312 (the figure for November-

Edmund Burke

e.burke@qmul.ac.uk

1

Queen Mary University of London, London, UK
December was not available at the time of writing). This is significantly higher than the figure for last year (which was 26,214). Faculty at more than 7000 academic institutions worldwide currently have immediate online access to articles in the Journal of Scheduling. During 2015, we had 247 new submissions to the journal, which is higher than this time last year when we had 166 new submissions. We are accepting approximately $20 \%$ of the submissions. The average time it has taken us to turn around an original submission (the time taken between submission and first decision) has been 70 days, a little more than 2 months. We will work to try and reduce this over 2016.

We would like to close by offering our thanks to all the people who have contributed to the success of the journal over the last year. Our Associate Editors and all our reviewers make such an important contribution to the journal, and we offer a big thank you to all of them. We are particularly grateful for the efforts of Matthew Amboy, Neil Levine and Supraja Yegnaraman at Springer for their efforts. During 2015, Sudha Subramanian moved on from Springer. We would like to take this opportunity to express our special thanks for all the work she has done for us as our editorial office assistant. In addition, we would like to thank Janaki Ramesh who took on the role of our editorial assistant for a few months. We would also like to welcome our new editorial office assistant, Venkat Ganesan. Finally, we would like to, once again, give a very special thank you to all our readers and authors. 